\title{
A produção do conhecimento científico: relação sujeito-objeto e desenvolvimento do pensamento
}

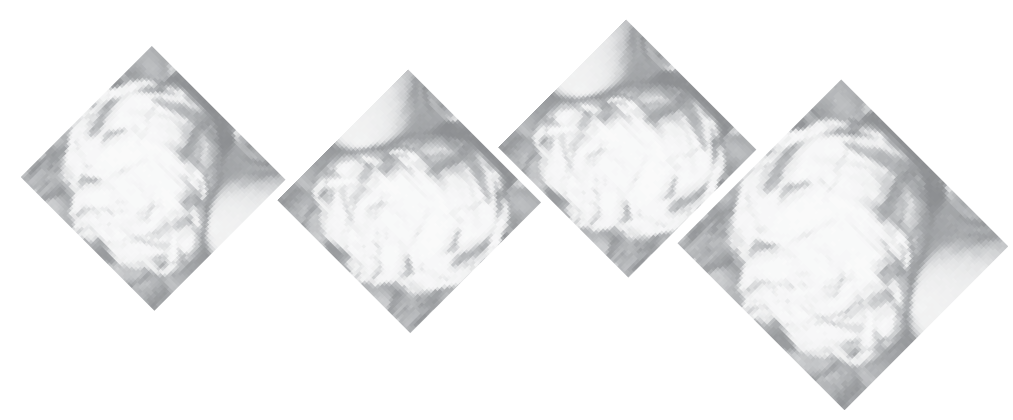

\author{
Angelo Antonio Abrantes ${ }^{1}$
}

Lígia Márcia Martins²

ABRANTES, A.A.; MARTINS, L.M. Scientific knowledge production: the subject-object relationship and thought development. Interface - Comunic., Saúde, Educ., v.11, n.22, p.313-25, mai/ago 2007.

This paper discusses the process of scientific knowledge production as an expression of the subject-object relationship, analyzing the problem according to the historical dialectical materialist theory of knowledge. Pursuing the objective of showing that the practical interaction between the subject and the object only sets the bases of scientific knowledge production through theoretical mediation, we reiterate the importance of school teaching and the assimilation of historically systematized knowledge, pointing to the one-sidedness that characterizes the conceptions that overemphasize "practice" to the detriment of "theory".

KEY WORDS: Knowledge production. Praxis. School instruction.

O presente estudo coloca em questão a produção do conhecimento científico como uma das expressões da relação sujeito-objeto, analisando-a à luz da teoria materialista histórico-dialética do conhecimento. Com o objetivo de demonstrar que a interação prática do sujeito com o objeto apenas fundamenta a produção do conhecimento científico pela mediação teórica, reiteramos a importância do ensino escolar e da apropriação dos saberes historicamente sistematizados, indicando a unilateralidade presente em concepções que enfatizam demasiadamente a "prática" em detrimento da "teoria".

PALAVRAS-CHAVE: Produção do conhecimento. Práxis. Educação escolar.

\footnotetext{
${ }^{1}$ Graduado em Psicologia; doutorando em Educação; docente, departamento de Psicologia, Universidade Estadual Paulista, Unesp, campus de Bauru; membro, Grupo de Pesquisa Pensamento e Linguagem; membro, Núcleo de Estudos e Pesquisa Psicologia Social e Educação: contribuições do marxismo (Neppem); subcoordenador, Núcleo de Estudos e Pesquisa em Educação Infantil - Nepei. Bauru, SP. <angeloaa@fc.unesp.br>

${ }^{2}$ Graduada em Psicologia; doutora em Educação; docente, departamento de Psicologia da Unesp/Bauru; membro, Grupo de Pesquisa Educação e Marxismo; coordenadora, Núcleo de Estudos e Pesquisa em Educação Infantil - Nepei. Bauru, SP. <ligiamar@fc.unesp.br>
}

\footnotetext{
${ }^{1}$ Av. Engenheiro Edmundo Coube, s/no 
... o homem reflete a realidade não apenas tal qual ela existe imediatamente, mas também como pode e deve ela ser para as necessidades sociais dele. Voltado, desde o início, para a satisfação de necessidades práticas do homem, o conhecimento cria, não raro, imagens dos objetos que não foram observados na natureza, mas devem e podem ser realizáveis na prática. A pesquisa autenticamente científica está imediatamente voltada

para a procura de formas e idéias segundo as quais o mundo deve ser mudado.

(Kopnin, 1978, p.228)

\section{Introdução}

A ciência moderna e, conseqüentemente, os ideários pedagógicos orientadores da prática educativa escolar têm afirmado, cada vez mais categoricamente, o papel do sujeito no processo de construção do conhecimento. A experimentação, a aprendizagem por problemas, o papel ativo do aprendiz e outros, são algumas máximas bastante em voga na atualidade.

Sabidamente, a tese segundo a qual o conhecimento é um meio de assimilação prática da realidade ocupa lugar de grande destaque também no materialismo dialético. Entretanto, a abrangência desta premissa, aliada a compreensões superficiais desta filosofia, tem permitido aproximações equivocadas entre a teoria do conhecimento dimanante do materialismo histórico-dialético e modelos pedagógicos altamente imbuídos de um realismo ingênuo e um pragmatismo subjetivista.

Tal constatação mobiliza-nos no sentido de conferir, neste texto, maior destaque aos princípios fundamentais da referida teoria. Para tanto, colocamos em foco, primeiramente, o conceito de práxis como unidade na relação sujeito/objeto para, na seqüência, versar sobre a construção do conhecimento científico acerca da realidade em suas vinculações com o desenvolvimento do pensamento empírico e do pensamento teórico.

Sobre a base desse desenvolvimento é que se descortinam as possibilidades para o entendimento materialista histórico-dialético das relações entre teoria e prática, pressuposto fundante da decodificação do real. Ocorre, porém, que tanto o desenvolvimento do pensamento quanto sua expressão epistêmica não se efetivam senão em condições de ensino $e$ apropriação dos saberes historicamente constituídos, dado que confere à educação escolar especial importância no âmbito da teoria materialista histórico-dialética do conhecimento.

\section{O conceito de prática e a relação sujeito/objeto}

Iniciemos pelo conceito de prática. No âmbito do materialismo dialético, a prática (ou práxis) dota-se de uma correspondência essencialmente histórica, universal, não possuindo uma correspondência automática $e$ 
imediata com a atividade particular de um dado indivíduo. Esta afirmação pode comportar, à primeira vista, um aparente paradoxo, qual seja: como conceber a práxis independente dos sujeitos particulares? A resposta a esta indagação requer a consciência de que:

O conhecimento está necessariamente imbuído no campo da atividade prática do homem, mas para garantir o êxito desta atividade ele deve relacionar-se necessariamente com a realidade objetiva que existe fora do homem e serve de objeto a essa atividade. (Kopnin, 1978, p.125)

Assim, a prática humana, na qual se inclui a produção do conhecimento, encerra sempre a relação entre o singular particular e o universal, sendo um fenômeno histórico, posto que as propriedades humanas subjetivas $e$ objetivas que a comportam resultam de amplas e complexas relações do homem com a natureza. Ao transformar a natureza, o homem se transforma, desenvolvendo habilidades, criando necessidades, tornando complexa sobremaneira sua atividade vital, isto é, constituindo-se como ser práxico. É na unidade articuladora entre a idéia $e$ a ação ou entre a teoria $e$ a prática que se efetiva a historicidade humana, concretizada no movimento de constituição da realidade social.

A construção práxica do conhecimento nos remete, portanto, à realidade histórica a se conhecer, visto que os indivíduos se desenvolvem em relações de apropriação da história contida nos objetos produzidos pelo homem $e$ nas relações estabelecidas entre eles na base de tais produções. Mas para uma efetiva compreensão da dimensão práxica do homem, outro preceito deve ser levado em conta, qual seja, a unidade inicial existente entre sujeito e objeto do conhecimento.

O sujeito cognoscitivo é o ser humano, entendido como sujeito coletivo, social e histórico, que produz conhecimento num determinado modo social de produção da existência, que, na atualidade, é o capitalista. Neste modo de produção, imperam as relações sociais de dominação e se efetiva a contradição entre capital $e$ trabalho, determinação histórica da qual faz parte a produção do conhecimento. O conhecimento humano produzido pelo ser social não está isento da tensão existente entre os pólos da citada contradição. No caso do materialismo histórico-dialético, busca-se a objetividade do conhecimento como contributo para a superação de uma realidade que, em sua essência, almeja acumular capital em detrimento do ser humano.

Por sua vez, o objeto a ser conhecido é a realidade na qual estão contidas as atividades humanas $e$ as contradições internas essenciais que the determinam o movimento histórico. Embora o objeto possa se apresentar ao pensamento como dado e acabado, nele estão contidas as relações sociais de produção expressas na contradição ontológica entre aparência e essência, determinante da necessidade da ciência e do método de se conhecer o real.

Portanto, a unidade sujeito - objeto reitera o papel do pensamento no processo de conhecer a realidade, ao mesmo tempo em que afirma a primariedade da realidade em relação ao pensamento. O conhecimento não emana nem do pólo concreto, representado pelo objeto (realidade), nem do 
pólo abstrato, representado pelo sujeito (pensamento), concentrando-se no movimento entre estes pólos, na relação entre a realidade e a consciência sobre ela. É na base desta tensão que se consolida o trabalho intelectual sobre a realidade, trabalho este que, ao colocar o real a descoberto, pela apreensão de suas múltiplas determinações sintetizadas na unidade aparência - essência, o representa e o expressa teoricamente.

\section{A construção do conhecimento sobre a realidade}

O conhecimento sobre a realidade objetiva origina-se de sensações/percepções. À base desses processos produz-se o conhecimento sensorial, ou a matériaprima do pensamento. Ao refletirem aspectos da realidade, possibilitam o aparecimento de uma imagem sensorial do mundo, com base na qual o homem começa a adquirir consciência, a conhecer os fenômenos da realidade, identificando, neles, propriedades, relações, origens, efeitos, etc. Este processo torna-se possível graças ao desenvolvimento da linguagem, quando o sensorial dado passa a ser representado sobre a forma de palavras, de idéias.

Portanto, no ser humano, o conhecimento sensorial jamais se expressa de modo puro, uma vez que resulta da interconexão entre conhecimento sensorial e linguagem. Referindo-se a esta interconexão, Petrovski (1985, p.292) considera que: "O pensamento surge do conhecimento sensorial sobre a base da atividade prática e o excede amplamente". Assim, toda prática humana excede a si mesma pois é mediada pelas ações e significações históricas, pelas objetivações das gerações antecedentes. É por meio dessa historicidade, inclusive, que a consciência dos homens se torna complexa e, em face dela, até mesmo as representações sensoriais mais elementares da realidade assumem a forma de pensamento. Portanto, inexiste prática (empiria) sem teoria (abstração), e teoria desprovida de prática, assertiva sobre a qual discorremos a seguir.

Ao analisar a impropriedade de conceber o sensorial e o racional como tipos distintos de conhecimento, identificando sensorial e empírico, e racional e teórico, Kopnin (1978, p.154) afirma:

Tanto o empírico como o teórico são níveis de movimento do pensamento. Diferem um do outro pela maneira e pelo aspecto em que neles é dado o objeto, pelo modo como é conseguido o conteúdo básico do conhecimento (...) (grifos dos autores)

O pensamento empírico, derivado direto da atividade sensorial do homem sobre os objetos da realidade é, indiscutivelmente, a forma primária de pensamento, levando ao conhecimento do imediato da realidade, isto é, ao conhecimento da realidade em suas manifestações exteriores. Pautando-se em princípios da lógica formal, o conhecimento empírico é absolutamente racional, revelando aspectos do objeto que se expressam pela categoria da existência presente, a exemplo de quantidade, qualidade, propriedade, medida, classe etc.

Diferentemente, o pensamento teórico apreende o objeto em suas relações internas e leis que regem o seu movimento, compreensíveis por meio de 
${ }^{3}$ Para mais

esclarecimentos sobre pensamento empírico e teórico, suas propriedades e desenvolvimento, sugerimos a leitura de Abrantes \& Martins, 2006. elaborações racionais dos dados dispostos pelo conhecimento empírico. Sua forma lógica é constituída pelo sistema de abstrações que explica o objeto, isto é, pelos conceitos, visando reproduzir o seu processo de transformação. Ultrapassando os limites do que é dado pela experiência, a racionalidade teórica não é simplesmente a forma ordenada (definidora, caracterizadora, classificatória, etc.) de expressão da experiência, mas sim o recurso, a ferramenta por meio da qual apreende-se um novo conteúdo, não passível de observação imediata do aparente ${ }^{3}$.

Portanto,

(...) a fronteira entre eles [pensamento empírico e teórico] é até certo ponto condicional: o empírico se transforma em teórico e o contrário, o que em certa etapa da ciência se considera teórico, torna-se empiricamente acessível em outra etapa mais elevada. (Kopnin, 1978, p.153)

Destaca-se, dessa citação, que a distinção entre o empírico e o teórico é condicional, e não espontânea ou automática. No plano filogenético, ela apenas tornou-se possível no período de maturidade científica, devido, portanto, aos avanços do pensamento científico; no plano ontológico, revela-se dependente da qualidade do desenvolvimento do pensamento, isto é, do desenvolvimento do pensamento como reflexo da realidade sob forma de abstrações ou de conceitos. Esta observação se justifica tendo em vista evitar o equívoco de se conceber o empírico e o teórico como dois degraus do conhecimento em detrimento da interpenetração existente entre eles em todas as etapas da produção de conhecimento.

Ainda segundo Kopnin (1978), as confusões existentes em relação ao movimento do conhecimento empírico ao teórico, como transição do concreto difuso ao concreto pensado pela mediação da abstração, fundamento do método marxiano de construção de conhecimento, têm deturpado a essência do pensamento teórico, desprovendo-o de sua objetividade, reduzindo-o à formação de abstrações (supostamente) vazias. Conforme esse autor, trata-se de uma tentativa de se compreender o conhecimento e o próprio pensamento humano segundo critérios e, portanto, nos limites do pensamento empírico, isto é, da experiência sensorial concreta. Por conseqüência, privilegia-se o conhecimento imediato em detrimento do conhecimento por conceitos, como se as abstrações fossem desprovidas de objetividade.

O conhecimento teórico é prenhe de conteúdos empíricos, que, por sua vez, se configuram como conhecimento verdadeiramente humano, por suas mediações teórico-abstratas. Esta é a síntese representativa da concepção materialista de práxis. Se, por um lado, as abstrações, os conceitos se distanciam do objeto, por outro lado, nada há mais apto para se aproximar da sua essencialidade, uma vez que o verdadeiro conhecimento não nos é dado pela contemplação viva ou pelo contato imediato. Por exemplo, o código genético (concreto pensado) jamais será apreendido imediatamente pela observação do sangue (concreto aparente); no entanto, o homem tornou-se capaz de conhecê-lo por meio do pensamento abstrato, ao distanciar-se temporariamente do concreto aparente, que, perdendo sua 
concretude superficial, adquire outro modo de existência: a existência como abstração. Esta, por sua vez, alcança outro nível de concretude representada por teses teóricas, equações, ideografias etc. que, em toda sua abstração $e$ abrangência, se aplicam e guiam a prática concreta sustentada por tais conhecimentos.

Os preceitos acima dispostos cumpriram a função de demonstrar que, para a teoria dialética do conhecimento, a interação prática com o objeto apenas fundamenta a construção do conhecimento científico pela mediação teórica. A natureza da relação prática é condicionada, a qualidade da prática ou da experiência sensorial depende do grau de desenvolvimento do pensamento do sujeito e, por outro lado, dos condicionantes históricos $e$ sociais dispostos na realidade objetiva que a sustenta. Tais constatações permitem-nos afirmar a unilateralidade presente em concepções que enfatizam demasiadamente a prática, absolutizando o empírico na construção do conhecimento.

\section{As relações entre teoria e prática}

O desenvolvimento do pensamento e, conseqüentemente, a produção de conhecimentos surgem de finalidades práticas. Ocorre, porém, que os fins não dimanam da sensorialidade experimental imediata, mas da consciência que possa o sujeito dispor sobre ela. O estabelecimento de finalidades, a identificação elou proposição de problemas práticos revelam-se, portanto, como atividades essencialmente teóricas. Assim sendo, para que as experiências práticas operem como mobilizadoras da construção do conhecimento real e efetivo (concreto), elas requerem um tipo de conhecimento muito especial: o conhecimento sobre um desconhecido que se necessita conhecer.

É em estreita unidade com a teoria materialista dialética do conhecimento que Saviani (1984, p.51) afirma a atividade investigadora como uma "incursão no desconhecido, que só se define por confronto com o conhecido", ou seja, sem o domínio do conhecido não é possível incursionar no desconhecido - dado que reafirma o papel do ensino para o desenvolvimento das capacidades do pensamento.

Portanto, em conformidade com a teoria materialista dialética do conhecimento, a proposição da experimentação ou da problematização como ponto de partida para a construção do conhecimento requer, a priori, um domínio conceitual básico. Caso contrário, a decodificação dos dados identificados pode não alçar a superação de um conhecimento imediato, circunscrito ao pensamento empírico.

Parece-nos evidente que, na epistemologia marxiana, os limites entre o ponto de partida e o ponto de chegada, no processo de construção do conhecimento, deixam de ser tão nítidos e cindidos. O que é normalmente classificado como ponto de partida, muitas vezes entendido como início quase absoluto de um problema que se impõe aos sentidos, é, na realidade, um momento do processo, que, se por um lado, deve ser tomado como inicial, por outro, se realmente se deseja produzir conhecimento, e não apenas reproduzir o imediato da realidade, deve ser entendido como 
resultado: momento de afirmação de um movimento que se inicia com anterioridade.

Neste sentido, o pressuposto de que a relação do sujeito do conhecimento com a realidade a ser conhecida (e transformada) se inicia pela prática social significa que o primeiro deve estreitar seus vínculos com ela para acompanhar o seu movimento e desvelar os determinantes ocultos em sua aparência. A apreensão da realidade em suas expressões precedentes $e$ presentes, aparentes e essenciais, é condição para o desenvolvimento do pensamento criativo, isto é, para a produção do conhecimento original sobre a realidade e para proposição de soluções aos problemas que nele se apresentam.

A prática social é, então, ao mesmo tempo, início do processo de construção do conhecimento e resultado (evidentemente que não apenas do conhecimento), síntese de contradições anteriores, $e$, como síntese, é portadora de uma complexidade e multilateralidade que não pode ser apreendida, como já foi afirmado, independente da atividade do pensamento. O pensamento é uma "prática" que permite superar o imediato $e$ as "facilidades" do empírico, sendo unidade entre teoria (idéias) $e$ atividade, que ocorre sempre sobre dadas condições histórico-sociais. Sintetiza contradições entre distintos conhecimentos produzidos e se impõe como resultado de uma luta de posições entre diferentes pensamentos que se negam ou que se afirmam.

Por outro lado, toda prática social é política e se expressa como resultado da contradição entre diferentes posições éticas de realização do real, contendo as dimensões técnica, científica, política e filosófica, que nem sempre se apresentam com limpidez no sensorial imediato.

Assim sendo, a vinculação que o sujeito do conhecimento deve realizar com a prática social não se limita ao contato pragmático com a realidade, ocorrendo somente se o indivíduo se apropriar dos fenômenos reais em suas múltiplas determinações. Para isto, é necessário conhecer os pensadores e os pensamentos, integrar-se, pela via das apropriações, às questões filosóficas e científicas que se objetivam em obras humanas imprescindíveis para que o sujeito do conhecimento tome consciência do seu tempo histórico, de suas possibilidades e limites. É preciso compreender o movimento e a gênese daquilo que se tem intenção de conhecer e transformar.

Portanto, a prática social pressupõe domínios teóricos e práticos e, assim sendo, quando o sujeito do conhecimento empreende um pensamento sobre a realidade, tendo em vista nela intervir, a qualidade de sua intervenção estará na dependência dos domínios conceituais que lhe estão disponibilizados, ou seja, o pensamento (como expressão da capacidade de conhecer) não é um bem espontâneo que se ativa automaticamente quando um indivíduo é exposto à realidade. Ele se desenvolve como conquista do ser social, em processos de ensino, cujo acervo resulta da história humana objetivada como riqueza pela ação práxica dos indivíduos que se apropriam dessas conquistas históricas. $\mathrm{O}$ indivíduo que pensa a realidade e sobre ela age, somente pode fazê-lo por meio da apropriação das conquistas históricas objetivadas.

A este indivíduo não é suficiente experimentá-la nos seu aspecto imediato 
e empírico; para ele, é fundamental apropriar-se dos resultados daquilo que o ser humano produziu de sistemas explicativos sobre a realidade, no recorte do que almeja conhecer e nas relações destes aspectos com questões mais gerais da sociedade e do desenvolvimento histórico do ser humano.

Desse modo, temos como fundamental a formação do sujeito do pensamento nos moldes do pensamento teórico que pressupõe a unidade contraditória entre teoria e prática, entre o abstrato e o concreto, entre o conhecimento empírico e o teórico. Quando afirmamos a unidade contraditória entre estes pólos distintos, não estamos pressupondo uma harmonia tranqüila entre eles, mas sim tensão e luta. As teorias, por exemplo, se desenvolvem no sentido de explicar a realidade, mas a realidade, em seu movimento, impõe desafios à teoria, apontando demandas que ela ainda não necessariamente possa contemplar, ou seja, a relação teoria prática supõe tensões e movimentos contínuos.

Se não devemos nos relacionar com a realidade com o pressuposto de conhecê-la com base em abstrações teóricas puras, sob o risco de cair no idealismo, não nos é possível também prescindir do conhecimento acumulado pelo ser humano, sintetizado nas abstrações teóricas. Do mesmo modo, se não podemos supervalorizar o empírico na relação com a realidade, sob o risco de cair num mecanicismo simplista ou num aprisionamento aos limites das representações superficiais do real, não nos é possível prescindir de material factual dela advindo para que o movimento do pensamento possa comprovar, recusar ou incorporar inovações aos sistemas teóricos explicativos dessa mesma realidade.

O pensamento teórico que visa apreender seu objeto na dinâmica dos aspectos passado, presente e futuro, não se caracteriza como um dote subjetivo pertencente a alguns indivíduos, mas como consciência histórica do movimento da humanidade do qual os indivíduos necessitam se apropriar, movimento este que se efetiva na relação entre a consciência como conquista do ser social, na qual se inclui a consciência sobre os meios de se conhecer a realidade.

Tais apropriações, por sua vez, não ocorrem espontaneamente, mas sim por meio dos processos educativos planejados para esse fim.

\section{O ensino, a apropriação $e$ a construção de conhecimentos}

A sistematização de ações educativas, as quais permitem que os conteúdos históricos façam parte da existência individual, é o que nutre a possibilidade de que o pensamento teórico se realize como mediação da relação do sujeito (que necessita conhecer o real) com a realidade a ser conhecida. Neste âmbito é que o pensamento se ocupa do conhecimento no que necessita ser explicado, produzido e sistematizado, cujo conteúdo implica aquilo que, na sociedade, merece ser transformado, ou seja, que considera a realidade como ela é, naquilo que ela tem a possibilidade de ser e no que se tem a intenção de que ela seja.

Utilizando como imagem o "mergulho" necessário na prática, acreditamos que um indivíduo imerso na realidade imediata, sem apoio de conceitos que sintetizam a experiência histórica do ser humano, corre o risco de se afogar 
numa imensidão de informações caóticas ou, no melhor dos casos, realizar avanços lentos e insignificantes à custa de muito se debater, como aquele que não foi ensinado a nadar e é atirado na água.

Neste sentido, não nos parece admissível omitir, na atividade educativa escolar, uma sólida formação teórica, ou a relegar como algo de menor importância frente ao imediatismo pragmático de nossos tempos.

Reafirmamos que a prática social, como entendida no materialismo histórico-dialético, não pode ser confundida com pragmatismo, forte responsável pelo empobrecimento da relação do indivíduo com a realidade, que ocorre de forma cada vez mais espontânea $e$ alheia às possibilidades históricas constituídas.

Os indivíduos necessitam de uma educação formal que possibilite a apropriação de conceitos de modo que se tornem instrumentos do pensamento na relação com a realidade, que dê ciência de seu movimento; do movimento dos próprios conceitos e do pensamento na busca de compreensão do real. Este desafio somente pode ser enfrentado com a organização intencional de atividades educativas que atuem com determinação neste sentido. Não é demais lembrar a importância do ensino para se efetivar a apropriação do conhecimento.

Parece-nos que discutir a produção do conhecimento, com base na afirmação da unidade contraditória que caracteriza a relação sujeito $e$ objeto, pressupõe considerar a necessidade de desenvolvimento do pensamento resultante da apropriação dos saberes historicamente produzidos, bem como abordar aspectos indissociavelmente implicados que se desdobram nessa discussão. Se, por um lado, a produção do conhecimento está implicada com o conhecimento já produzido - e, portanto, com processos de ensino escolar; por outro, o processo de construção desse conhecimento não está imune à determinação das necessidades práticas do ser humano. Assim, a dimensão da aplicação prática do conhecimento produzido não pode estar alheia ao conhecimento científico que está em processo de construção. Tais proposições reiteram a indissociável relação entre a qualidade do ensino e a qualidade da produção de conhecimentos.

$\mathrm{Na}$ apreensão da relação entre a aplicação do conhecimento produzido $e$ o processo de produção do conhecimento, não nos é possível isolar nenhum destes pólos, apesar de haver especificidades referentes a cada um deles. Não é possível negar que, de acordo com a atividade que se realiza, uma das dimensões acima citadas é preponderante em relação à outra, apesar da possibilidade que têm de se objetivarem como um todo.

Kopnin (1978, p.226) afirma entender, como essencial do conhecimento humano, o seu movimento enquanto investigação:

A investigação científica é um processo imediatamente voltado para a obtenção, no pensamento, de novo resultado não só para um sujeito dado, mas para o sujeito em geral. Ademais, para entender a essência do conhecimento, é necessário vê-lo como investigação, porquanto nesta se manifesta justamente a particularidade característica do conhecimento humano: o movimento do pensamento no sentido de resultados efetivamente novos. $A$ investigação científica enquanto ato do 
conhecimento se realiza à base da interação prática do sujeito com o objeto. Ela constitui uma forma teórica de apreensão do objeto pelo sujeito, nela se manifesta especialmente a natureza social do sujeito. (grifos dos autores)

Se considerarmos que o processo de intervenção prática deve estar pautado em conhecimentos científicos, se entendemos que o conhecimento, de modo geral, deve ser considerado investigação - como movimento do pensamento no sentido de resultados novos - podemos afirmar que não somente a investigação científica deve ser caracterizada como teórica, mas também sua aplicação como prática, uma vez que a apreensão efetiva do objeto da ação humana pressupõe a identificação de sua dimensão teórica. Assim sendo, a própria aplicação prática do conhecimento, mesmo considerando-se a sua especificidade, deve se caracterizar como ação investigativa.

Na produção de conhecimento científico que, na afirmação de Kopnin (1978), manifesta especialmente o caráter social do sujeito, os elementos da relação acima referida permanecem. No entanto, o pólo predominante é outro, qual seja, o dos limites do conhecimento e do processo empreendido para sua superação, considerando-se as possibilidades históricas e as condições em que se realiza a atividade de produzir conhecimento.

O autor afirma que a investigação científica começa pelo problema, pois ele é a "expressão das necessidades práticas que impulsionam o pensamento no sentido da procura de novos resultados" (Kopnin, 1978, p.230). Assim sendo, o problema está associado ao que não foi apreendido pelo pensamento, mas que se faz necessário apreender, e, dessa forma, está direcionado para o futuro sem desconsiderar as conquistas que se fizeram presentes.

O que se entende por problema na discussão do autor é, pois, algo distinto do sentido que lhe é atribuído no senso comum. Na vida cotidiana, nos defrontamos com uma infinidade de problemas e nos defrontamos com toda espécie de questões empíricas sem que este tipo de experiência tenha qualquer relação com um problema científico.

... como definição inicial de problema aquilo que não foi apreendido pelo homem mas que é necessário apreender. (...) No entanto, não é todo o não-conhecido que constitui o problema científico, que não é simplesmente um não conhecimento, mas um conhecimento do não conhecimento. Não se escolhe como problema qualquer objeto que o pesquisador queira conhecer, o que este objeto constitui, as leis a que ele se subordina, mas só um objeto sobre o qual o conhecimento é realmente possível sob as condições vigentes. (Kopnin, 1978, p.230) (grifos dos autores)

O problema científico vincula-se justamente com aquele, já referido, conhecimento sobre um desconhecido que se necessita conhecer. Esta qualidade de problema pressupõe conhecer o que foi realizado como conhecimento que o antecede, o que é necessário e o que é possível apreender pela atividade investigativa. Ora, estes pressupostos somente 
podem ser atendidos com o conhecimento dos fatos práticos relacionados ao objeto do conhecimento e das premissas da ciência que o sustenta.

Para a colocação de um problema, além de ser necessário conhecimento do que lhe é antecedente, é fundamental que se conheçam, também, as vias de sua solução. O problema posto em uma investigação científica se caracteriza como um sistema teórico cujo princípio unificador, ao invés de se constituir exclusivamente de teses autênticas de uma dada teoria, é uma questão que nelas se sustenta. Implicada naquilo que o autor denomina de juízo questão (problema de pesquisa), está a resposta provável (hipótese) a ele, idéia diretriz que pode conduzir a um conhecimento novo. No processo de investigação científica, as teses prováveis estão em conexão com as autênticas.

O provável é o conhecimento de um grau de precisão e fundamentabilidade, o autêntico, de outro grau, superior; no processo de movimento do pensamento, a probabilidade se converte em autenticidade, enquanto que esta gera nova probabilidade. Neste sentido, cabe à probabilidade um papel ativo no domínio do objeto, na apreensão de suas propriedades. (...) a probabilidade, assim como a autenticidade, que são momentos subordinados à veracidade objetiva, não podem ser divorciadas e contrapostas à verdade. O papel delas pode ser entendido somente em face da análise das leis de obtenção do conteúdo objetivo verdadeiro pelo pensamento. (Kopnin, 1978, p.263)

O autor nomeia a organização da investigação científica como teoria vazia, no sentido de que é necessário que ela seja "preenchida" de realidade. Para isto, é preciso ter consciência das vias de solução do problema colocado, para "motivar" na realidade aquilo que é necessário conhecer; portanto, a relação com a realidade no desenvolvimento do processo de produção do conhecimento não é nunca isenta e espontânea, é uma relação essencialmente teórica. Não é possível, pois, construir conhecimento novo sendo prisioneiro do empírico. Segundo ele:

Chama-se teoria a um vasto campo de conhecimento, que descreve e explica um conjunto de fenômenos, fornece o conhecimento dos fundamentos reais de todas as teses lançadas, e reduz os descobrimentos em determinado campo e as leis a um princípio unificador único.

(Kopnin, 1978, p.237)

Considerando a diversidade de aspectos envolvidos na proposição de um problema científico, podemos retomar a reflexão sobre a relação entre o processo de produzir conhecimento e a aplicação do conhecimento produzido como unidade contraditória. Se, no primeiro caso, considerando a especificidade da atividade, as teses prováveis têm preponderância em relação às autênticas, apesar de se constituírem como unidade, no segundo caso, a situação se inverte, na aplicação prática do conhecimento, as teses autênticas, até aquele dado momento, devem ser preponderantes em relação às prováveis. 
A delimitação cognitiva do problema, tanto no processo de produção de conhecimento, que pode se dar pela investigação científica, quanto na intervenção prática pautada por saberes científicos, deve contemplar, como conteúdo, a unidade também contraditória entre teses autênticas e teses prováveis, sintetizadas em um sistema teórico que se movimenta em direção à veracidade objetiva. Outrossim, a referida delimitação apenas se efetiva à luz de rigorosos processos de ensino - condição imprescindível para o desenvolvimento da capacidade humana práxica.

\section{Considerações finais}

Tendo em vista a formação dos indivíduos que se efetiva pela educação escolar, a colocação de problemas como meio de mobilizar a ação pedagógica pode desempenhar papel importante somente quando resultar de um processo que se vincule à colocação de problemas aos parâmetros acima expostos, mesmo que ainda não se caracterizem como problemas científicos nos moldes de produção de conhecimentos novos.

o problema, para fazer parte do processo educativo e se constituir como parte do processo de construção do conhecimento concreto, isto é, que apreenda o fenômeno de modo multilateral e profundo, não pode se limitar a uma questão do senso comum, mas caracterizar-se como problema humano (teórico). Problemas produzidos pela atividade práxica humana não podem ser confundidos com o pragmatismo das questões mais imediatas que se apresentam de forma aparentemente espontânea aos sentidos.

Eles se colocam ao ser humano, tanto no processo de produzir conhecimento quanto no de sua aplicação prática, e se constituem, sempre, na unidade entre as dimensões teóricas e práticas. Ambas as atividades dependem de que o pensamento teórico, possibilidade histórica objetivada, se expresse na existência dos indivíduos como força no sentido de conhecer o real.

As ações educativas que afirmam a importância dos problemas no processo de aprendizagem devem considerar o problema na complexidade que procuramos evidenciar - pelo menos, os que se dizem pautados pela epistemologia materialista histórico-dialética -, sob o risco de iniciar o processo educativo partindo de pseudoproblemas, e neles permanecendo de forma circular até o momento de apresentar, de forma burocrática $e$ externa, uma colagem de recortes de conhecimento que versam sobre determinado tema, ou seja, chegando a um pseudoconhecimento.

Os resultados advindos de concepções ingênuas de prática e de problema, apesar de acoplados à supervalorização do termo "pesquisa", não caracterizam atitude investigativa nos termos considerados no materialismo histórico dialético. Defrontar qualquer aluno com um problema que não tem condições de conhecer em sua profundidade, bem como as vias de sua solução, é crueldade, ainda que travestida com roupagens de liberdade discente no processo de construção autônoma do seu próprio conhecimento. 


\section{Referências}

ABRANTES, A.A.; MARTINS, L.M. Relações entre conteúdos de ensino e processos de pensamento. Educ. Marx., n. 1, 2006. Disponível em: <http://www2.fc.unesp.br/revista_educacao/arquivos/ Relacao_entre_conteudos_de_ensino_e_processos_de_pensamento.pdf>. Acesso em: 11 nov. 2006.

KOPNIN, P.V. A dialética como lógica e teoria do conhecimento. Rio de Janeiro: Civilização Brasileira, 1978.

PETROVSKI, A. Psicologia general: manual didático para os institutos de Pedagogia. Madri: Editorial Progresso, 1985

SAVIANI, D. Escola e democracia. São Paulo: Cortez/Autores Associados, 1984.

ABRANTES, A.A.; MARTINS, L.M. La producción del conocimiento científico: relación sujeto - objeto y desarrollo del pensamiento. Interface - Comunic., Saúde, Educ., v.11, n.22, p.313-25, mai/ago 2007.

El presente estudio discute la producción del conocimiento científico como expresión de la relación sujeto - objeto analisando la referida relación sobre la base de la teoría materialista histórico dialéctica del conocimiento. Plantea demostrar que la interacción práctica del sujeto con el objeto fundamenta la producción del conocimiento científico gracias a la mediatización teórica. El proceso de análisis afirma la importancia de la enseñanza escolar y de la apropiación de los saberes históricamente constituídos, señalando la unilateralidad presente en concepciones que destacan en demasía la "práctica" en detrimento de la "teoría".

PALABRAS CLAVE: Producción del conocimiento. Práxis. Enseñanza escolar. 


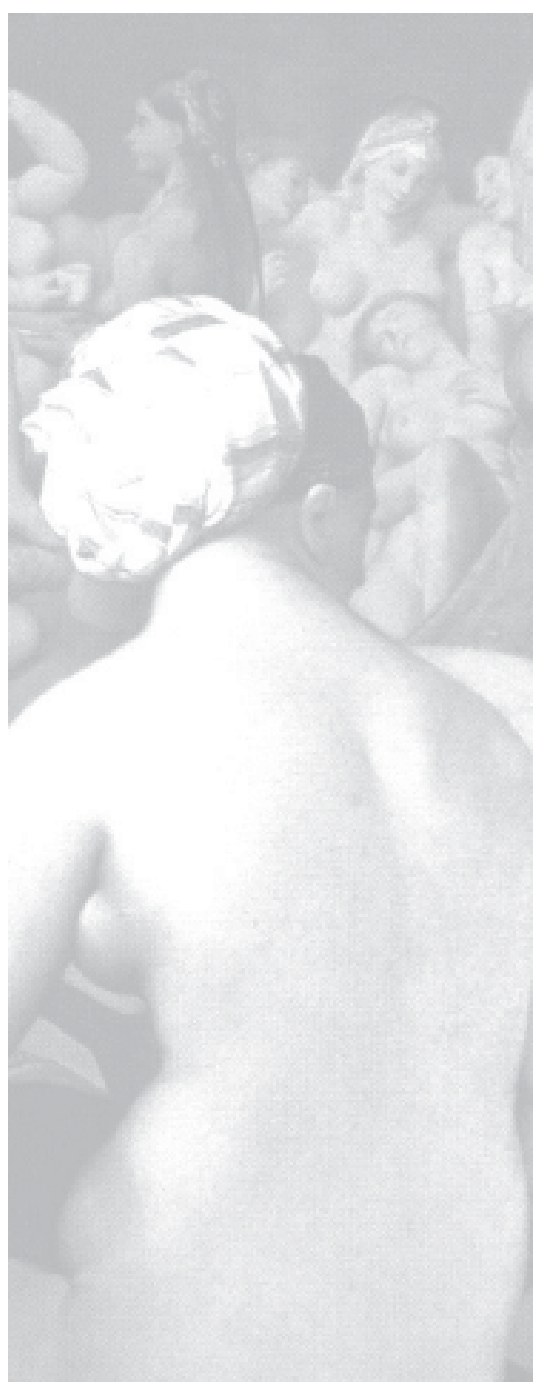

